\title{
Simulating reinforcement corrosion-induced strain in concrete using expansive grout
}

\author{
Prasanna Kumar Behera ${ }^{1, *}$, K. Mondal $^{2}$ and Sudhir Misra ${ }^{1}$ \\ ${ }^{1}$ Department of Civil Engineering, and \\ ${ }^{2}$ Department of Materials Science and Engineering, Indian Institute of Technology, Kanpur 208 016, India
}

\begin{abstract}
The present study attempts to obtain the critical strains in concrete induced on account of reinforcement corrosion by simulating the expansive pressure of corrosion products using grout. Surface strains induced in hollow concrete cylinders due to expansion of grout filled inside the hollow portion were continuously monitored to experimentally validate the well-known thick-walled uniform cylinder model used in reinforcement corrosion problems. The study shows that expansive grout could effectively simulate the internal pressure generated in accelerated corrosion tests, and can be used as a means of obtaining critical strains in relatively shorter duration in laboratory studies.
\end{abstract}

Keywords: Concrete, corrosion, critical strain, expansive grout, steel.

CORROSION of steel in reinforced concrete (RC) constructions is a major concern related to deterioration of the structure. Service life models for RC structures vulnerable to rebar corrosion are often based on the three stages as given in Figure 1, and are briefly discussed in the following paragraphs.

(a) Initiation phase refers to the time taken for depassivation of the protective film on the surface of the bars on account of chloride attack or carbon dioxide penetration, and ends with the initiation of corrosion.

(b) Stress build-up phase occurs after corrosion initiation, and involves the formation and deposition of corrosion products on the bars. In this phase, the expansive pressure generated due to the restrained expansion at the steel-concrete interface generates hoop stresses in concrete leading to the initiation of longitudinal cracks.

(c) Rapid corrosion and deterioration phase, marked by rapid crack growth and spalling of cover concrete.

It has been widely accepted that the formation of corrosion-induced longitudinal crack is the maximum extent of deterioration that can be accepted in an $\mathrm{RC}$ member ${ }^{1,2}$. Determination of service life involves the estimation of time-to-cracking of concrete cover, a stage at which corrosion in steel reaches a critical level (referred as the critical corrosion amount, CCA), which results in the critical surface strain (in short critical strain) on the cover. Rea-

*For correspondence. (e-mail: bprasannakumar99@gmail.com) listic estimation of critical strains and the corresponding CCAs is important to accurately predict the time-tocracking in concrete structures ${ }^{3}$.

In concrete, corrosion of reinforcement starts with localized attack, and gradually spreads all around the steel giving rise to uniform expansive pressure at the steel-concrete interface ${ }^{4}$. In most of the laboratory studies, corrosion of centrally embedded reinforcement in concrete (lollipop specimens) is accelerated by impressing a direct current between the reinforcing steel and stainless steel in salt solutions ${ }^{3-7}$. To obtain CCA and associated pressure, strains on the concrete surface are monitored in these accelerated corrosion tests $(\mathrm{ACTs})^{3,4}$. However, depending on the test conditions, it takes several hours to determine these strains ${ }^{5}$. Corrosion in an ACT leads to uniform deposition of rust around the circumference of steel, and thus exerts uniform internal pressure on the surrounding concrete ${ }^{8,9}$.

\section{Critical strain as a property of concrete}

The method adopted in the literature to model the uniform corrosion is often a thick-walled cylinder approach (Figure 2), where the internal walls of the cylinder are subjected to uniform radial pressure ${ }^{9-21}$. Details of the model are presented in an earlier work of the present authors ${ }^{9}$. Radial stress $\left(\sigma_{r}\right)$ and hoop stress $\left(\sigma_{\theta}\right)$ at any distance $r$ inside the concrete cylinder having inner radius (b) equal to radius of rebar, and outer radius (c) equal to inner radius plus concrete cover, and subjected to internal radial pressure $P$, are given by

$$
\sigma_{r}=\alpha+\frac{\beta}{r^{2}} \text { and } \sigma_{\theta}=\alpha-\frac{\beta}{r^{2}}
$$

where

$$
\alpha=\frac{P b^{2}}{c^{2}-b^{2}} \text { and } \beta=\frac{-P b^{2} c^{2}}{c^{2}-b^{2}} \text {. }
$$

For plane strain modelling, $\sigma_{z}=\mu\left\{\sigma_{r}+\sigma_{\theta}\right\}$, where $\sigma_{\mathrm{z}}$ is the stress along length of the cylinder and $\mu$ is the Poisson ratio of concrete. 


$$
\begin{aligned}
& \text { At } r=c, \sigma_{\theta, c}=\frac{2 P b^{2}}{c^{2}-b^{2}}, \sigma_{r, c}=0 \\
& \text { and } \sigma_{z, c}=\mu^{*}\left\{\frac{2 P b^{2}}{c^{2}-b^{2}}\right\} .
\end{aligned}
$$

From the theory of elastic mechanics, hoop strain on the outer surface (i.e. at $r=c$ ) can be obtained as

$$
\varepsilon_{\theta, c}=\left[\frac{1-\mu^{2}}{E}\right] *\left\{\frac{2 P b^{2}}{c^{2}-b^{2}}\right\},
$$

where $E$ is the elastic modulus of concrete. At the onset of crack, hoop stress on the surface of concrete is equal to tensile fracture strength of concrete $\left(f_{\text {cr }}\right)$, which can be taken as $60 \%$ of the splitting tensile strength of concrete $^{22}$.

Therefore

$$
\frac{2 P b^{2}}{c^{2}-b^{2}}=f_{\text {cr }} \text { (limiting } \sigma_{\theta, c} \text { in eq. (2) to } f_{\text {cr }} \text { ). }
$$

The critical strain $\left(\varepsilon_{\mathrm{cr}}\right)$ on the surface of concrete at crack initiation can be obtained as

$$
\varepsilon_{\mathrm{cr}}=f_{\mathrm{cr}} *\left[\frac{\left(1-\mu^{2}\right)}{E}\right] \text {. }
$$

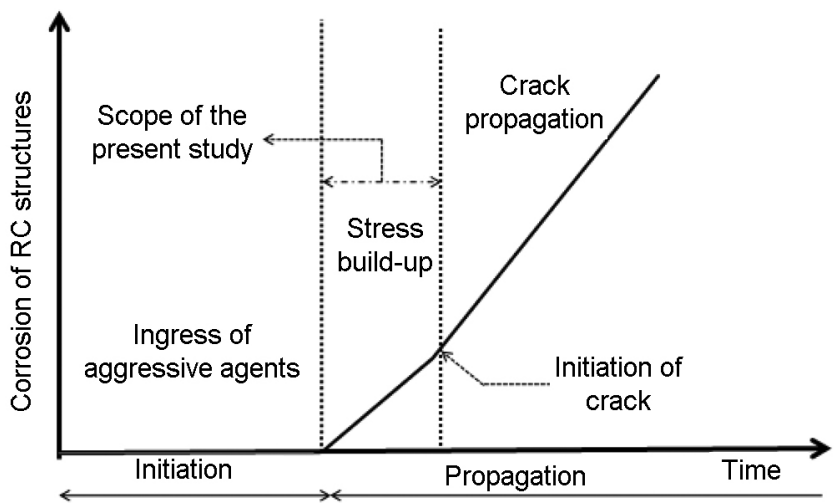

Figure 1. Typical service life model due to reinforcement corrosion in reinforced concrete $(\mathrm{RC})$ structures ${ }^{1,2}$.

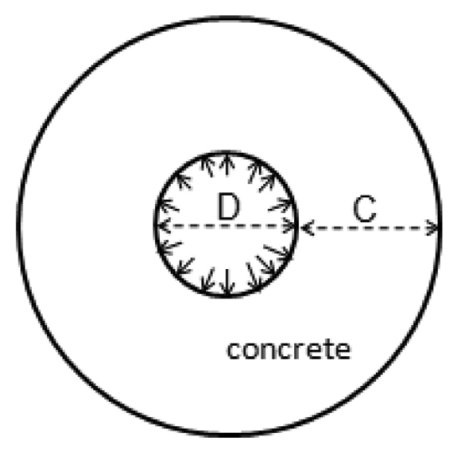

Figure 2. Thick-walled concrete cylinder subjected to internal pressure. $C$ is the cover and $D$ is the diameter of the bar.
Using eq. (5), the critical strain at crack initiation can be theoretically estimated if the tensile fracture strength of the concrete is known.

It has been proposed in our earlier work ${ }^{9}$ that CCA can be evaluated using a comprehensive methodology in which detailed information about the corrosion products, like thickness of rust, phases and their densities was used along with analytical axi-symmetric plane strain formulation of a thick-walled cylinder. The critical strain determined from eq. (5) was used for evaluating critical pressure and radial displacement of the inner periphery of concrete. Later, the volume dilation obtained from the radial displacement and information regarding phases of rust were used together to estimate CCA. Thus, the proposed methodology is based on estimating critical strain using eq. (5), and hence the experimental validation of the equation gains significance. Therefore, in the present study, an experimental check on the reliability of eq. (5) has been carried out by comparing theoretical estimates with experimentally obtained values.

Few inferences from eq. (5) are worth mentioning in this context. First, it does not consist of any term that represents the source of internal pressure at the interface. Therefore, any process which could exert internal radial thrust similar to corrosion pressure can be adopted in validation studies. Secondly, the critical strain depends only on the properties of concrete $\left(E, \mu\right.$ and $f_{\text {cr }}$ ), but not on the geometry of the cylindrical specimen. It can be clearly observed that eq. (5) does not contain any term that takes the geometry of the cylindrical specimen into account. This study seeks to verify these assertions by (i) using two mechanisms to introduce internal pressure (expansive grout and accelerated corrosion tests), and thereby exploring the possibility of estimating critical strains by simulating corrosion-induced pressure using expansive grout, which could serve as a faster means of determining critical strains in laboratory studies, and (ii) using specimens having different geometrical and strength properties. To experimentally estimate the critical strains, surface strains generated in concrete are continuously monitored by creating the internal pressure at the interface using expansive grout in annular hollow cylinders. The results obtained through the time versus strain plots in grout tests are verified using ACT.

\section{Experimental methods}

\section{Materials}

Tests were performed with three different concrete mixes. Tables 1 and 2 provide details of the mix proportions and properties of concrete mixes respectively. The proportions of the chemical admixtures were finalized by testing the workability of some trial mixes pertaining to various mix proportions used in the study. It was observed that 
RESEARCH ARTICLES

Table 1. Details of materials used in the study

\begin{tabular}{lccccc}
\hline & \multicolumn{3}{c}{ Mix proportion of constituents $\left(\mathrm{kg} / \mathrm{m}^{3}\right.$ of concrete) } & \\
\cline { 2 - 4 } Mix & Cement & Water & Fine aggregate & Coarse aggregate* & Chemical admixture $\left(1 / \mathrm{m}^{3}\right)$ \\
\hline M1 & 303 & 166 & 766 & 1163 & 3.03 \\
M2 & 334 & 167 & 762 & 1138 & 3.34 \\
M3 & 394 & 169 & 702 & 1132 & 3.94 \\
\hline
\end{tabular}

*Maximum size of coarse aggregate is $10 \mathrm{~mm}$, i.e. one-fourth of the minimum dimension of test specimen.

Table 2. Properties of concrete mixes used in the study

\begin{tabular}{lccccc}
\hline Mix & $\begin{array}{c}\text { 28-Day compressive } \\
\text { strength }(\mathrm{MPa})\end{array}$ & $\begin{array}{c}\text { 28-Day splitting tensile } \\
\text { strength }\left(f_{\mathrm{t}} ; \mathrm{MPa}\right)\end{array}$ & $\begin{array}{c}\text { Fracture strength } \\
f_{\mathrm{cr}}=0.6^{*}\left(f_{\mathrm{t}} ; \mathrm{MPa}\right)\end{array}$ & $\begin{array}{c}\text { Elastic modulus* } \\
E(\mathrm{MPa})\end{array}$ & $\begin{array}{c}\text { Poisson } \\
\text { ratio } \mu\end{array}$ \\
\hline M1 & 30.76 & 2.46 & 1.47 & 25,000 & 0.13 \\
M2 & 36.94 & 3.49 & 2.09 & 27,386 & 0.13 \\
M3 & 44.62 & 3.91 & 2.34 & 29,580 & 0.13 \\
\hline
\end{tabular}

${ }^{\#}$ Hwang and Rizkalla ${ }^{22}$. Calculated using $E=5000 *\left(f_{\mathrm{ck}}\right)^{1 / 2}$ by taking $f_{\text {ck }}$ as 25,30 and 35 MPa for M1, M2 and M3 respectively ${ }^{23}$.

Table 3. Material safety data sheet of the expansive grout ${ }^{27}$

\begin{tabular}{lc}
\hline Properties & Details \\
\hline Composition & Percentage by weight \\
Silicon dioxide & 5.1 \\
Aluminium oxide & 1.6 \\
Ferric oxide & 2.5 \\
Calcium oxide & 89.6 \\
& \\
Physical/chemical characteristics & \\
Specific gravity & 3.2 \\
Appearance & Grey powder \\
Odour & No Odour \\
Safety details & \\
Explosive & No \\
Toxic gases & No \\
Environmentally safe & Yes \\
\hline
\end{tabular}

approximately $1 \%$ of the cement proportion (by weight) would yield the 'medium' degree of workability (according to IS $456: 2000)^{23}$ for the mixes. Thus, appropriate dosages of chemical admixture were added to the mixes to maintain the slump of concrete in the range $80 \pm 10 \mathrm{~mm}$, whereas the compressive and tensile strengths were determined directly using $150 \mathrm{~mm}$-sized cubes of concrete, and cylinders of $100 \mathrm{~mm}$ length and $200 \mathrm{~mm}$ height (split cylinder test) respectively ${ }^{24,25}$. The elastic modulus of concrete $(E)$ was estimated using the following expres$\operatorname{sion}^{23}$

$$
E=5000 * \sqrt{f_{\mathrm{ck}}}\left(\mathrm{N} / \mathrm{mm}^{2}\right)
$$

where $f_{\text {ck }}$ is the 28-day characteristic compressive strength of concrete $(\mathrm{MPa})$. The Poisson ratio of concrete ${ }^{26}$ was considered to be 0.13 and $f_{\text {cr }}$ was taken as $60 \%$ of split- ting tensile strength, determined experimentally ${ }^{22}$. An expansive grout, that acquires the property of expansion when mixed with water, was used to create internal pressure inside the concrete. Table 3 shows the properties of the grout. Once the grout was filled inside the hollow portion, the expansive pressure gradually increased with time.

\section{Experimental programme}

Two series (1 and 2) of experiments were performed. For series 1 , hollow concrete specimens were cast with concrete with a central hole of diameter equal to that of reinforcing steel (Figure $3 a$ ). Annular space of the hollow concrete cylinders, which was later filled with an expansive grout, represents the reinforcing bar in a real structure, whereas thickness of the cylinder represents the cover. They were cast and moist-cured for a day before the formwork was removed and the specimens were kept in water for 28 days. During the casting of hollow concrete specimens, plain steel bars of required dimensions were centrally embedded. These bars were removed from the specimens $10 \mathrm{~h}$ after the casting (before the concrete hardened). The quantity of grout was determined based on the dimensions of the hollow portion, and it was checked that the amount of grout actually consumed was acceptably close to the predetermined volume. This has enabled to minimize the possibility of honey-combing inside the specimen. Figure $3 b$ shows the dimensions of RC specimens used in accelerated corrosion tests (series2). Plain mild steel bars having $0.12 \% \mathrm{C}, 0.38 \% \mathrm{Mn}$, $0.15 \% \mathrm{Si}, 0.05 \% \mathrm{~S}, 0.05 \% \mathrm{P}, 98.9 \% \mathrm{Fe}$ (all in wt\%) along with other trace elements were used in series 2 . Various cover/diameter $(C / D)$ ratios of specimens in both series were obtained by keeping their internal diameters 
$\left(D_{i}\right)$ as 12,16 and $20 \mathrm{~mm}$ and maintaining the outer diameter $\left(D_{0}\right)$ at $100 \mathrm{~mm}$ for all the specimens. The circumferential extensions at the outer surfaces of cylindrical concrete specimens were measured using an extensometer. Thus, the hoop tensile strain over the entire perimeter was obtained during the tests. It should be pointed out that any local variation prior to the formation of cracks was adequately accounted for.

\section{Testing}

Series-1: After moist curing, the specimens were dried using hot air for almost an hour before filling the hollow portion with expansive grout. The grout was prepared by mixing the powder with water (maintaining a constant water-binder ratio of 0.3 throughout), and was filled in the hole at the centre of the hollow concrete cylinder. Tests were carried out on specimens M1-12, M1-16, M120, M2-12, M2-16, M2-20, M3-12, M3-16 and M3-20, where M1, M2 and M3 represent the mixes and the numbers 12,16 and 20 indicate the diameter $(\mathrm{mm})$ of the hole. Duplicates of each combination were tested, and the average values are considered. In all tests, the extensometer was attached at mid-depth to avoid end-effects (Figure 4 ), and circumferential extension on the surface of the concrete cylinder was continuously recorded in every test using a commercially available data acquisition system. Circumferential strain was calculated by dividing the observed extension by the initial outer circumference $\left(\pi^{*} D_{0}\right)$ of the specimen, and used as a parameter for further discussions. The events of crack formation were confirmed with steep rise in extensometer readings.

Series-2: ACTs were conducted on RC samples using impressed current technique ${ }^{9}$. Relevant salient aspects of details of the experiments and subsequent analyses are well described in our previous work ${ }^{9}$. However, few important aspects corroborating the fact that critical strain

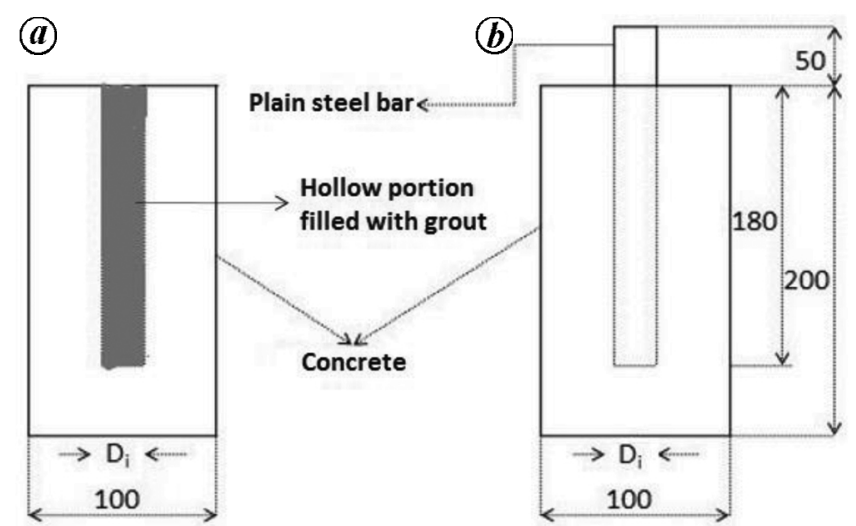

Figure 3. $\quad \boldsymbol{a}$, Hollow cylinder used in expansive grout test. $\boldsymbol{b}$, Lollipop cylinder used in 'reliability of simulation' study. $D_{i}$ is the diameter of rebar (all dimensions are in $\mathrm{mm}$ ). was accumulated on the surface due to the formation of rust phases at the interface are worth explaining in this context. Interfaces of the cracked $\mathrm{RC}$ samples were carefully examined using sophisticated microscopic and spectroscopic techniques ${ }^{9}$. Uniform rust formation was confirmed by careful cross-sectional analysis, and therefore it could be assumed that uniform corrosion pressure was exerted at the interface. Presence of various phases in the rust samples was observed in spectroscopic (Fourier transform infrared (FTIR) and Raman) results. These phases being more voluminous than the parent metal $(\mathrm{Fe})$ exert an expansive pressure on the surrounding concrete? which in turn causes development of circumferential strain in concrete, and finally the accumulated surface strain results in crack initiation once it exceeds a critical level. The ensuing crack due to volume dilation was confirmed through scanning electron microscopy (SEM) also.

To verify the rate of strain development obtained in grout tests, two sets of specimens, one being hollow cylinders and other being lollipop RC specimens, were cracked by exerting internal pressure using expansive grout and ACT respectively. Table 4 provides the details of the materials used and the impressed current technique. The diameter of the rebar in lollipop specimen and diameter of the hole in the hollow specimen were equal $(20 \mathrm{~mm})$. The expansive grout test was conducted on the hollow concrete specimen as described earlier. Circumferential extensions were recorded in ACT using the extensometer. Since, the corrosion products themselves were responsible for cracking the RC specimen in ACTs, the recorded extensions depicted the rate at which the corrosion products exerted pressure in the cracking phenomenon. However, this was strictly limited to the impressed current technique, which is a common way of accelerating corrosion in RC specimens for laboratory studies.

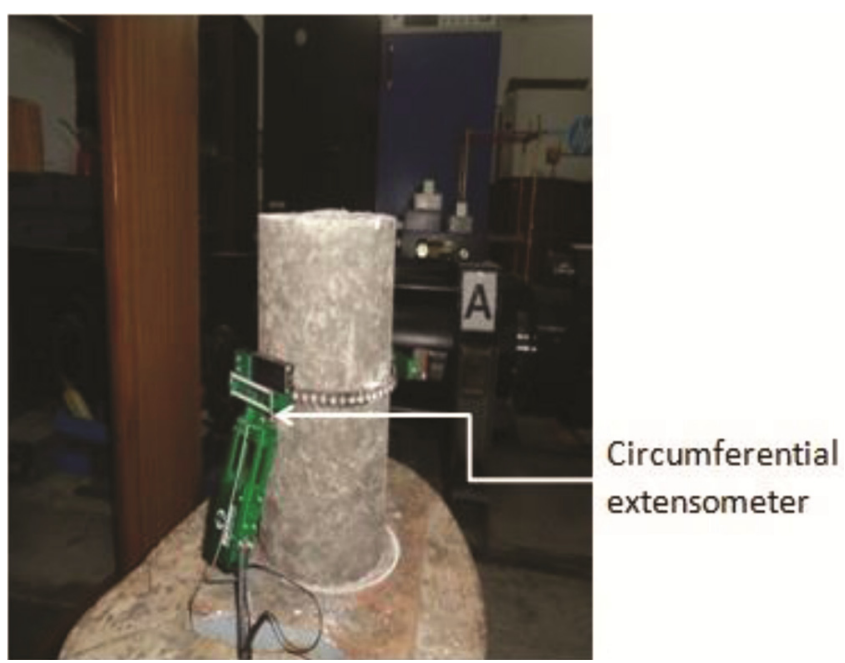

Figure 4. Measurement of circumferential strain in concrete specimens.

CURRENT SCIENCE, VOL. 118, NO. 3, 10 FEBRUARY 2020 

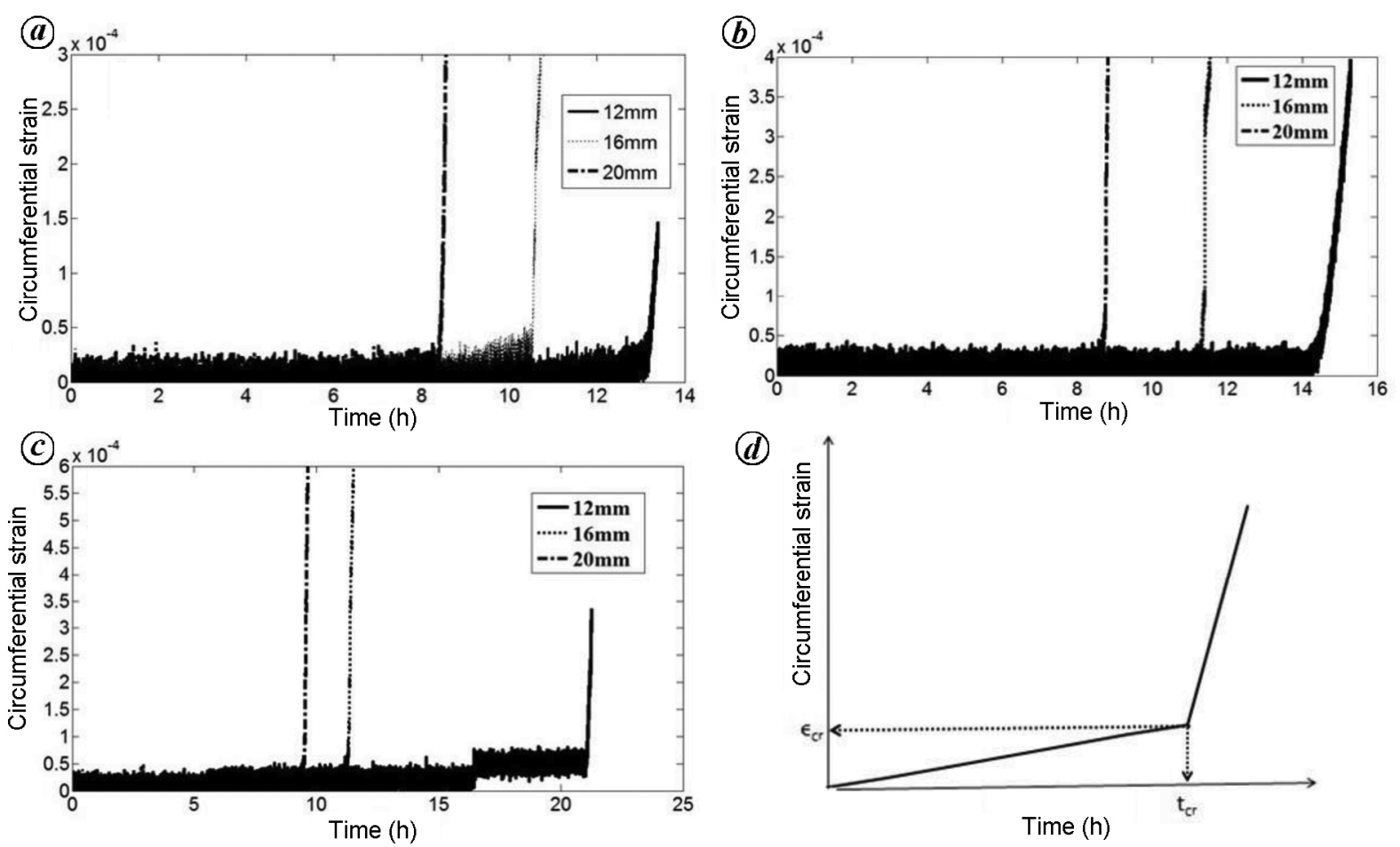

Figure 5. $\boldsymbol{a}-\boldsymbol{c}$, Circumferential strain versus time variation during the expansive grout tests of specimens $(\boldsymbol{a}) \mathrm{M} 1,(\boldsymbol{b}) \mathrm{M} 2$ and $(\boldsymbol{c})$ M3 specimens. $\boldsymbol{d}$, Schematic representation of the general trend in time versus circumferential strain. $\varepsilon_{\mathrm{cr}}$ is the critical strain and $t_{\mathrm{cr}}$ is the time to cracking.

Table 4. Details of materials and accelerated corrosion tests (ACTs) in 'reliability of simulation' experiments

\begin{tabular}{|c|c|c|c|c|c|}
\hline \multirow[b]{2}{*}{ Concrete mix details } & \multicolumn{4}{|c|}{ Mix proportion $\left(\mathrm{kg} / \mathrm{m}^{3}\right)$} & \multirow[b]{2}{*}{$\begin{array}{c}\text { Chemical admixture }\left(1 / \mathrm{m}^{3}\right) \\
4.03\end{array}$} \\
\hline & $\begin{array}{c}\text { Cement } \\
403\end{array}$ & $\begin{array}{l}\text { Water } \\
222\end{array}$ & $\begin{array}{c}\text { Fine aggregate } \\
638\end{array}$ & $\begin{array}{c}\text { Coarse aggregate } \\
1135\end{array}$ & \\
\hline \multirow[t]{5}{*}{ Properties of concrete } & \multicolumn{3}{|c|}{ 28-Day compressive strength (MPa) } & 29.65 & \\
\hline & \multicolumn{3}{|c|}{ Splitting tensile strength $\left(f_{\mathrm{t}} ; \mathrm{MPa}\right)$} & 2.21 & \\
\hline & \multicolumn{3}{|c|}{ Tensile fracture strength $f_{\mathrm{cr}}=0.6^{*} f_{\mathrm{t}}(\mathrm{MPa})$} & 1.32 & \\
\hline & \multicolumn{3}{|c|}{ Static modulus of elasticity $(\mathrm{E} ; \mathrm{MPa})$} & 25,000 & \\
\hline & \multicolumn{3}{|c|}{ Poisson ratio $(\mu)$} & 0.13 & \\
\hline \multirow[t]{4}{*}{ Impressed current technique details } & \multicolumn{3}{|l|}{ Anode } & \multicolumn{2}{|c|}{ Rebar in concrete } \\
\hline & \multicolumn{3}{|l|}{ Cathode } & \multicolumn{2}{|c|}{ Stainless-steel plate } \\
\hline & \multicolumn{3}{|l|}{ Electrolyte } & \multicolumn{2}{|c|}{$3.5 \% \mathrm{NaCl}+3.5 \% \mathrm{FeCl}_{3}$} \\
\hline & \multicolumn{3}{|c|}{ Current density $\left(\mathrm{mA} / \mathrm{cm}^{2}\right)$} & 1.41 & \\
\hline
\end{tabular}

${ }^{\#}$ Calculated using $E=5000 *\left(f_{\text {ck }}\right)^{1 / 2}$ by taking $f_{\text {ck }}$ as $25 \mathrm{MPa}$.

\section{Results and discussion}

\section{Series-1: Expansive grout tests}

Figure $5 a-c$ shows plots of circumferential strains obtained from recorded extensions over time in series- 1 . It may be noted that the strain increases gradually for a certain period of time, followed by a sudden increase. Based on the data of all specimens, a schematic representation of the strains with time is shown in Figure $5 d$, and critical strains at the time of crack initiation and the corresponding time are determined (Figure $5 d$ ) for the point of steep rise (in strain values). The circumferential strain at the crack initiation is considered to be the experimental 'critical strain', and is used as a basis for validation.

Critical strain: Theoretical critical strains used for estimating critical corrosion were calculated using eq. (5), and found to be 57.8, 75.3 and 77.9 microstrains for the three concrete mixes, M1, M2 and M3 respectively (Table 5). For illustration, the theoretical critical strain of M1 concrete is evaluated as

$$
\varepsilon_{\mathrm{cr}}=1.47 *\left[\frac{\left(1-0.13^{2}\right)}{25,000}\right]=57.8 \times 10^{-6} .
$$


Table 5. Circumferential extension readings at crack initiation and the critical strain values

\begin{tabular}{|c|c|c|c|c|c|c|c|}
\hline Mix & $\begin{array}{c}\text { Cover to } \\
\text { diameter } \\
\text { ratio }\end{array}$ & $\begin{array}{c}\text { Theoretical critical } \\
\text { strains }\left(\times 10^{-6}\right)\end{array}$ & $\begin{array}{c}\text { Time to } \\
\text { cracking }(\mathrm{h})\end{array}$ & $\begin{array}{c}\text { Experimental } \\
\text { circumferential } \\
\text { extension }(\mu \mathrm{m}) \text { at } \\
\text { the onset of cracks }\end{array}$ & $\begin{array}{l}\text { Experimental } \\
\text { critical strains } \\
\left(\text { extension } / \pi D_{0}\right) \\
\quad\left(\times 10^{-6}\right)\end{array}$ & $\begin{array}{l}\text { Average } \\
\text { experimental } \\
\text { critical strains } \\
\quad\left(\times 10^{-6}\right)\end{array}$ & $\begin{array}{l}\text { Deviation } \\
\text { percentage }\end{array}$ \\
\hline \multirow[t]{3}{*}{ M1 } & 3.67 & 57.8 & 13.0 & 17.31 & 55.13 & 55.2 & 4.7 \\
\hline & 2.62 & & 10.5 & 17.89 & 56.97 & & \\
\hline & 2.00 & & 8.5 & 16.83 & 53.59 & & \\
\hline \multirow[t]{3}{*}{ M2 } & 3.67 & 75.3 & 14.5 & 22.19 & 70.67 & 72.1 & 4.4 \\
\hline & 2.62 & & 11.0 & 23.58 & 75.09 & & \\
\hline & 2.00 & & 9.0 & 22.17 & 70.61 & & \\
\hline \multirow[t]{3}{*}{ M3 } & 3.67 & 77.9 & 21.0 & 26.71 & 85.06 & 74.4 & 4.7 \\
\hline & 2.62 & & 11.5 & 22.13 & 70.47 & & \\
\hline & 2.00 & & 9.5 & 21.35 & 67.99 & & \\
\hline
\end{tabular}

Table 5 also shows the critical strain values obtained experimentally through series-1. It can be observed that the experimental values are in excellent agreement with those predicted theoretically. Thus, the corrosion pressure modelling using thick-walled cylinder concepts is experimentally verified in this study through grout tests.

Moreover, it can be seen from Table 5 that the experimental critical strain values for M1 are 55.1, 57.0 and 53.6 microstrain for $C / D$ ratios of $3.67,2.62$ and 2 respectively. From the values for mixes M2 and M3 also, it is clear that the critical strain is independent of the geometry of the specimen, and depends only on the properties of concrete.

Time to cracking: Table 5 also shows the time-tocracking for the different specimens estimated using the procedure given in Figure $5 d$. It can be clearly observed that $t_{\mathrm{cr}}$ depends on strength of the concrete, the cover provided and the $C / D$ ratio. The time-to-cracking increases with the strength of concrete, the cover provided and the $C / D$ ratio. In specimens having larger diameter hole, the cover of concrete would be less (since the outer diameter is same $(100 \mathrm{~mm})$ in all the specimens $)$. Moreover, more expansive grout would be needed for filling in case of a larger diameter hole, leading to faster accelerated cracking process.

Cracking patterns: During testing, cracks were observed on the surface of the specimens after a certain period, indicating the accumulation of critical strain in concrete. These cracks were present all along the length of the specimen, and were similar to reinforcement corrosioninduced cracks in concrete. Figure 6 shows two views of a representative specimen after formation of a crack in series- 1 .

Rate of strain development in test series-1: From the plot of M3-12 (Figure $5 \mathrm{c}$ ), the building of stress in concrete at different stages during the course of the test can be clearly observed. For example, at an elapsed time of $16 \mathrm{~h}$, a rise in extension values occurs. However, no visual sign of crack was observed during the experiment. Even, the steepness of the plot had not risen after $16 \mathrm{~h}$. This implies that concrete could resist the hoop stress till this stage. The strain energy was released through crack formation at $21 \mathrm{~h}$ in this test. As the diameter of the hole is less and the grade of concrete is high in the M3-12 specimen, the response of concrete towards the expansive pressure as a function of time has been effectively simulated in this specimen.

Validation of the model: From the results, it is evident that the theoretical critical strains are slightly higher than the experimentally obtained values. However, the average percentage deviation is less than 5 and thus it can be inferred that the critical strains are well predicted from axi-symmetric plane strain formulation of the thickwalled uniform cylinder model.

\section{Series-2: ACTs}

The volume dilation at the interface has been confirmed through the optical and SEM photomicrographs ${ }^{9}$. Presence of rust phases has been confirmed using FTIR plots as well ${ }^{9}$. Based on these spectroscopic and photomicrographic results, it can be considered that the samples have cracked due to accumulation of critical strain on the surface (Figure $7 a$ and $b$ ). Figure $7 a$ shows a SEM photomicrograph of the cross-section of the cylindrical specimen along with the corroded products on the rebar after ACT. Figure $7 b$ depicts the FTIR spectrum of rust showing the presence of different rust phases ${ }^{9}$. Depending on the geometry and strength of concrete used, cracking of the RC samples in this series of tests occurred in 24-48 h from the start.

Figure 8 shows plots of strain development in both the expansive grout test and ACT. The experimental critical strains (microstrain) were obtained as 50.7 and 48.7 in 


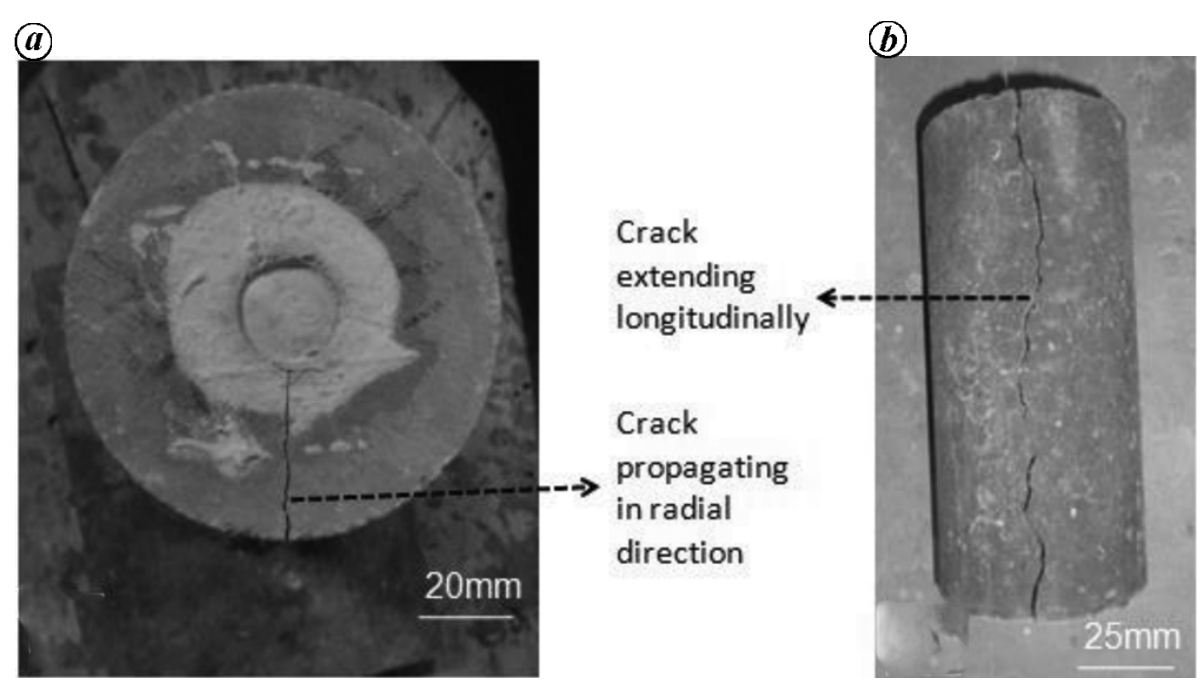

Figure 6. Crack patterns: (a) Top view of a cracked hollow cylinder in the expansive grout test. (b) Longitudinal view of cracked specimen in the expansive grout test.
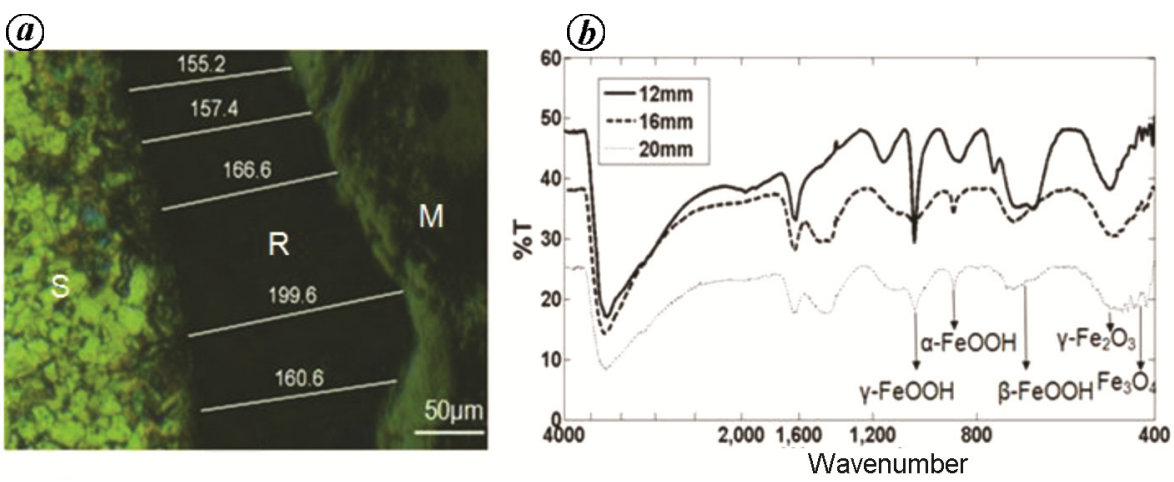

Figure 7. $\boldsymbol{a}$, Typical optical photomicrographs of interface (M, Mounting; R, Rust; S, Steel). $\boldsymbol{b}$, Fourier transform infrared spectra showing phases in rust samples of $\mathrm{M} 2 \mathrm{RC}$ specimens (\% $\mathrm{T}, \%$ transmittance).

expansive grout test and ACT respectively. Whereas the theoretical critical strain was

$$
\varepsilon_{\mathrm{cr}}=1.32 *\left[\frac{\left(1-0.13^{2}\right)}{25,000}\right]=51.9 \times 10^{-6}
$$

Thus, the theory holds valid from actual corrosion test viewpoint too. Moreover, from Figure 8 , it can be inferred that the build-up of internal pressure and associated circumferential strain in ACT are similar to that of the expansive grout test, and hence the simulation using grout can be taken to be experimentally reliable. After the onset of crack, the strain values increased at a higher rate in the expansive grout test, whereas in the impressed current technique the growth was relatively slow and steady as the corrosion process at this stage is governed by the mass transport mechanism from cathode to anode. Moreover, in the case of actual corrosion, the crack growth will be a function of several factors like ingress of corrosives, various reactions for the formation of different corrosion products on long-duration exposure, temperature at the crack tip, etc. Interestingly, during grout tests the initiation and propagation of crack are due to the rapid swelling action of grout. However, in the impressed current technique, the swelling action is limited by the formation kinetics of the rust phases, which involves diffusion of corrosives as well as the reaction mechanisms. Hence, it is natural that the formation and propagation of cracks in the case of impressed current technique is sluggish. Since the aim of this study is to find the critical strain experimentally (i.e. till the onset of crack), the present simulation using grout is experimentally justifiable. Figure 9 shows the corrosion-induced cracks. It can be seen that the characteristics are similar to those shown for the cracks formed with expansive grout action in this study.

From Figures $5 a-c$ and 8 , it can be observed that rapid crack growth has started when the hoop stress on the surface reaches $60 \%$ of splitting cylinder strength in both the expansive grout test and ACT. Therefore, it can be understood that the critical condition (onset of crack or initiation of rapid crack growth) pertains to the state at which 


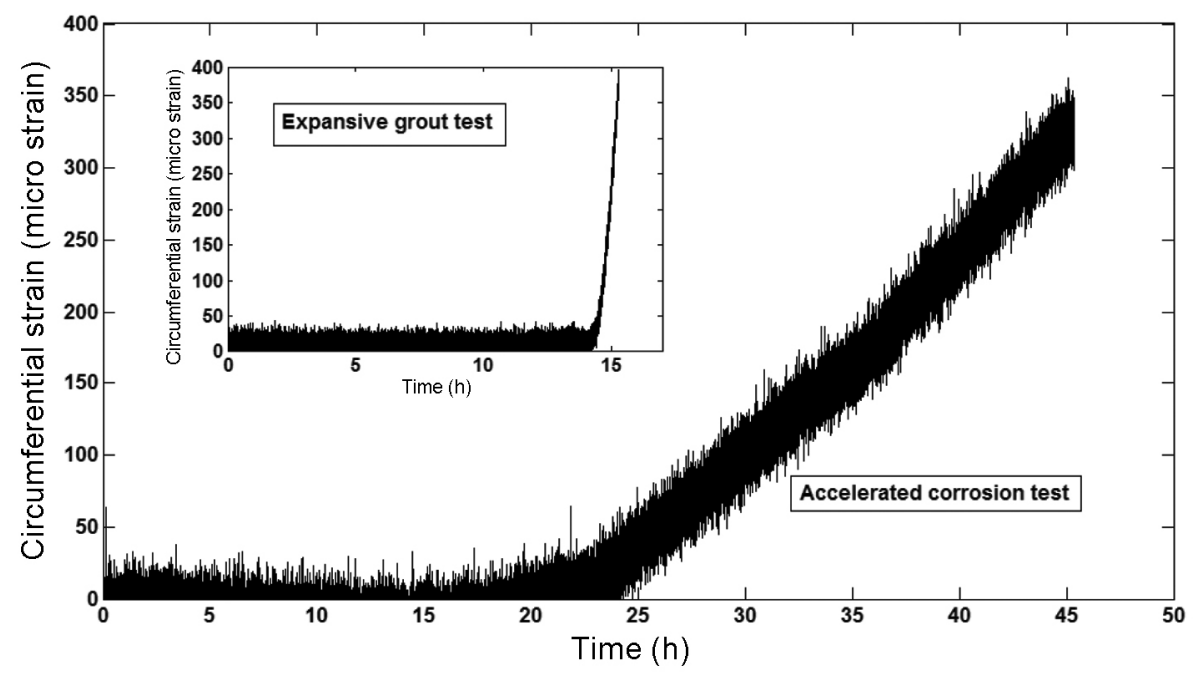

Figure 8. Rate of strain development in the expansive grout test and accelerated corrosion test (ACT).
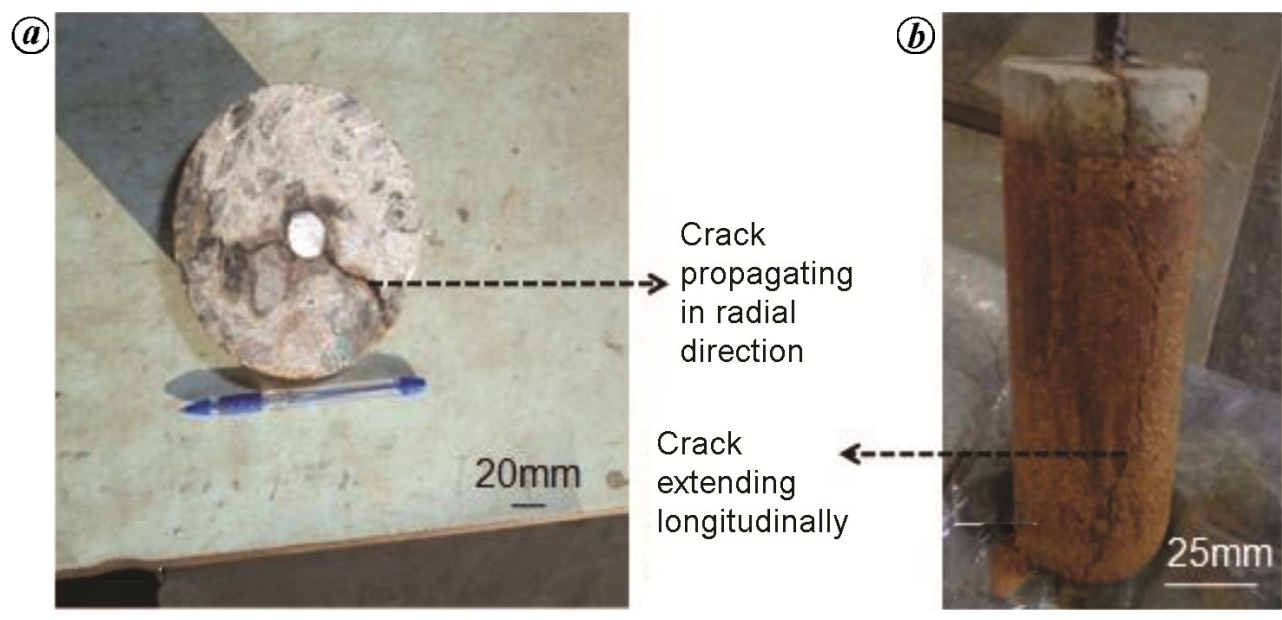

Figure 9. Crack patterns: (a) Top view of a sliced concrete disc obtained from a cracked lollipop specimen, (b) Longitudinal view of the cracked lollipop specimen in ACT.

the surface hoop stress reaches fracture strength (i.e. $60 \%$ of splitting cylinder strength). Hence it can be concluded that any estimate of critical corrosion based on the splitting cylinder strength would be higher than the actual critical corrosion. In other words, accurate estimates can be obtained by considering tensile fracture strength of concrete but not splitting tensile strength of concrete.

Effectiveness of expansive grout test: The time to cracking $\left(t_{\mathrm{cr}}\right)$ in ACT is nearly $24 \mathrm{~h}$, whereas for a similar mix and diameter of the rebar, $t_{\mathrm{cr}}$ in the grout test is typically around $14 \mathrm{~h}$. Thus, the two tests differ only in the time at which crack initiation takes place but not in the experimental critical strain values (50.7 and 48.7 microstrain). Therefore, in the context of estimating the critical strain of concrete in reinforcement corrosion problems, expansive grout test is effective compared to the conventional ACTs. Figure 10 schematically shows that the critical strain at longitudinal crack initiation, which is usually obtained through ACTs, can be found in much lesser time using expansive grout test $\left(t_{\mathrm{cr}}\right.$, grout tests $<t_{\mathrm{cr} \text {, АCT }}<$ $\left.t_{\mathrm{cr} \text {, natural corrosion }}\right)$.

Sometimes in ACTs, hazardous chemicals like $\mathrm{FeCl}_{3}$ may have to be used for faster cracking of the concrete specimen, whereas the expansive grout tests are safe. For ACT, an experimental set-up comprising a cathode, electrolyte and power supply is required, whereas, the expansive grout test is much simpler as it just needs a hollow concrete cylinder filled with the grout. This facilitates applicability of the expansive grout test in actual field conditions to evaluate the critical strain of concrete, particularly during the inspection of RC structures subjected to rebar corrosion. The physics and trend of cracking in concrete are similar in both cases. The future of the research in the field is more on the evaluation of time frame to such cracking. Therefore, it is important to find 


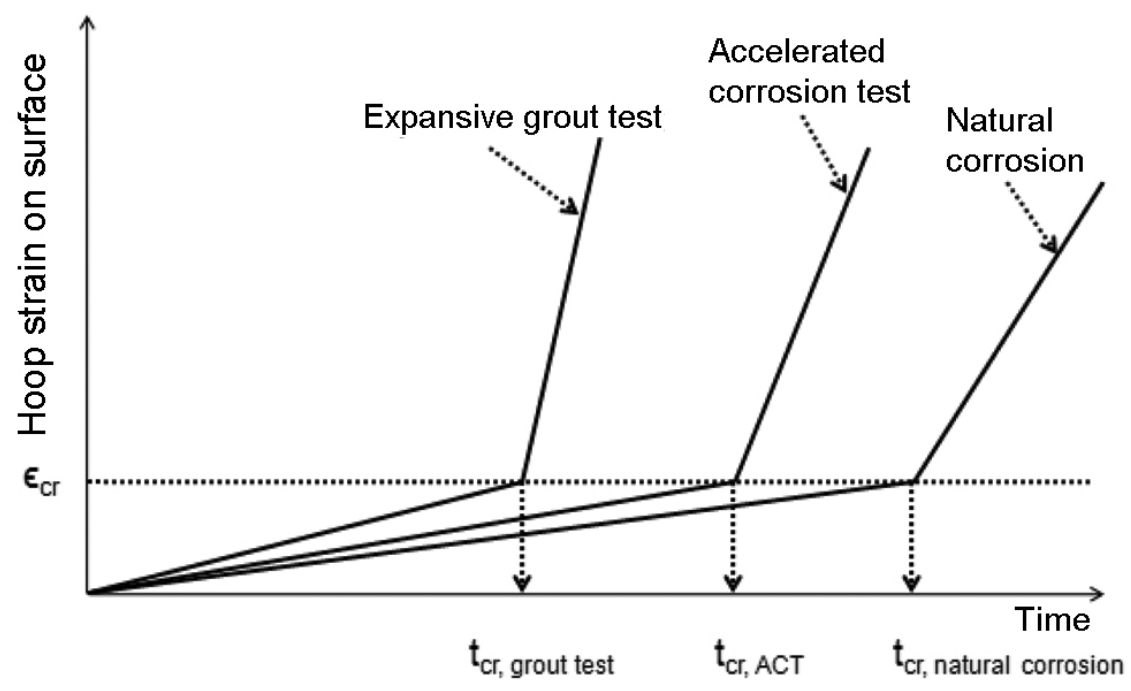

Figure 10. Schematic representation of comparison of typical cracking times in natural corrosion, ACT and expansive grout test.

the empirical relation between the time for cracking in case of the grout test and the cracking time as experienced in case of ACT, and finally with the actual service condition. However, the present study provides a framework to achieve this greater goal.

\section{Conclusion}

This study aims to evaluate the critical strains on the surface of cylindrical concrete specimens using expansive grout, and verify them with the theoretical estimates made using well-known thick-walled cylinder modelling in case of reinforcement corrosion problems, which in turn forms a basis in estimating CCA needed to initiate longitudinal cracks. The objective has been achieved by continuously monitoring the hoop strain on the surface of concrete subjected to internal pressure.

The assumption of plane strain condition in thickwalled cylinder modelling represents the essential physics involved in the reinforcement corrosion-induced cracking process in RC structures. Though the plane strain assumption slightly overestimates the critical strains, the average deviation between experimental and theoretical values is found to be $4.6 \%$ in this study, which is nominal at microstrain level.

Till the onset of cracks, expansive grout can effectively simulate the pressure generated at the concrete-steel interface due to steel corrosion, and can be used as a means to estimate critical strain in a relatively shorter time.

For a given concrete mix, critical stain due to the internal radial pressure depends only on the properties of concrete. For a given $C / D$ ratio, concrete having higher strength has higher critical strain. However, time to cracking depends on both properties of concrete as well as the $C / D$ ratio.
1. Uomoto, T. and Misra, S., Deterioration of concrete beams and columns caused by corrosion of reinforcing steel bars. In Fourth International Conference on Durability of Building Materials and Components, Singapore, 1987, pp. 420-426.

2. Yokozeki, K., Motohashi, K., Okada, K. and Tsutsumi, T., A rational method to predict the service life of RC structures in marine environment. In Proceedings of the 4th CANMET/ACI International Conference on Durability of Concrete, SP170-40, American Concrete Institute, Farmington Hills, MI, USA, 1997, pp. 777-799.

3. Oh, B. H., Kim, K. H. and Jang, B. S., Critical corrosion amount to cause cracking of reinforced concrete structures. ACI Mater. J., 2009, 106, 333-339.

4. Behera, P. K., A study on the onset of rebar corrosion induced longitudinal cracks in reinforced concrete structures. MTech. thesis, Department of Civil Engineering, Indian Institute of Technology, Kanpur, 2015.

5. Ahmad, S., Bhattacharjee, B. and Wason, R., Experimental service life prediction of rebar corroded reinforced concrete structure. $A C I$ Mater. J., 1997, 94, 311-316.

6. Maaddawy, T. A. E. and Soudki, K., Effectiveness of impressed current technique to simulate corrosion of steel reinforcement in concrete. J. Mater. Civil Eng., 2003, 15, 41-47.

7. Munoz, A., Andrade, C. and Torres, A., Corrosion products pressure needed to crack the concrete cover. In Advances in Construction Materials (ed. Grosse, C. U.), Springer, Heidelberg, Germany, 2007, pp. 359-370.

8. Malumbela, G., Alexander, M. and Moyo, P., Model for cover cracking of RC beams due to partial surface steel corrosion. Const. Build. Mater., 2011, 25, 987-991.

9. Behera, P. K., Moon, A. P. K., Mondal, K. and Misra, S., Estimating critical corrosion for initiation of longitudinal cracks in $\mathrm{RC}$ structures considering phases and composition of corrosion products. J. Mater. Civ. Eng., ASCE, 2016, 28, 04016158-1-12.

10. Bazant, Z. P., Physical model for steel corrosion in concrete sea structures - application. J. Struct. Div., ASCE, 1979, 105, 11551166.

11. Chernin, L. and Val, D. V., Prediction of corrosion induced cover cracking in reinforced concrete structures. Constr. Build. Mater., 2011, 25, 1854-1869.

12. Liu, Y. and Weyers, R. E., Modeling the time to corrosion cracking in chloride contaminated reinforced concrete structures. $A C I$ Mater. J., 1998, 95, 675-681. 
13. Pantazopoulou, S. J. and Papoulia, K. D., Modeling covercracking due to reinforcement corrosion in RC structures. J. Eng. Mech., ASCE, 2001, 127, 342-351.

14. Wang, X. H. and Liu, X. L., Modeling effects of corrosion on cover cracking and bond in reinforced concrete. Mag. Concr. Res., 2004, 56, 191-199.

15. Bhargava, K., Ghosh, A. K., Mori, Y. and Ramanujam, S., Modeling of time to corrosion induced cover cracking in reinforced concrete structures. Cem. Concr. Res., 2005, 35, 2203-2218.

16. Sobhani, J. and Ramezanianpour, A. A., Chloride induced corrosion of RC structures. Asian J. Civ. Eng., Build. Housing, 2007, 8, 531-547.

17. Chen, D. and Mahadevan, S., Chloride induced reinforcement corrosion and concrete cracking simulation. Cem. Concr. Compos., 2008, 30, 227-238.

18. Chernin, L., Val, D. V. and Volokh, Y. K., Analytical modeling of concrete cover cracking caused by corrosion of reinforcement. Mater. Struct., 2010, 43, 543-556.

19. Lu, C., Jin, W. and Liu, R., Reinforcement corrosion induced cover cracking and its time prediction for reinforced concrete structures. Corros. Sci., 2011, 53, 1337-1347.

20. Maaddawy, T. E. and Soudki, K., A model for prediction of time from corrosion initiation to corrosion cracking. Cem. Concr. Compos., 2007, 29, 168-175.

21. Oteino, M. B., Beushuasen, H. D. and Alexander, M. G., Modeling corrosion propagation in reinforced concrete structures - a critical review. Cem. Concr. Compos., 2011, 33, 240-245.
22. Hwang, L. W. and Rizkalla, S. H., Effective tensile stress strain characteristics of reinforced concrete. In Proceedings of the Canadian society of Civil Engineering Structural Concrete Conference, Natural Science and Engineering Research Council of Canada, Ottawa, Canada, 1983.

23. BIS, Indian Standard: 456, Plain and reinforced concrete - code of practice, Bureau of Indian Standards, New Delhi, 2000.

24. BIS, Indian Standard: 516, Method of tests for strength of concrete, Bureau of Indian Standards, New Delhi, 1959 (R2004).

25. BIS, Indian Standard: 5816, Splitting tensile strength of concrete method of test, Bureau of Indian Standards, New Delhi, 1999 (R2004).

26. Gere, J. M., Mechanics of Materials, Thomson Learning Inc., Belmont, USA, 2004, 6th edn, p. 913.

27. https://www.crackamite.com/msds (accessed on 8 March 2019).

ACKNOWLEDGEMENTS. The experiments were carried out in the Structural Engineering Laboratory of IIT Kanpur, and the support extended by staff of the Laboratory is gratefully acknowledged. We thank the Hydraulics and Pneumatics Company, Rajasthan, for providing the expansive grout.

Received 8 March 2019; revised accepted 10 October 2019

doi: $10.18520 / \mathrm{cs} / \mathrm{v} 118 / \mathrm{i} 3 / 401-410$ 